\title{
Rol de los
}

\section{comunicadores}

corporativos en el

establecimiento

de una agenda

economica

informativa de

calidad

\section{RESUMO}

La construcción de la agenda económica informativa por parte casi unilateral de las empresas, a través de promotores intencionales de hechos y contenidos, podría ser reflejo de un nuevo fenómeno tentativamente denominado comunicación medial corporativa, similar al de la desinformación, pero cuyo objeto es obtener de parte del público la percepción que sea más favorable para los intereses de la compañía, lo que a la larga en vez de favorecer podría perjudicar la reputación y la gestión de negocios de las empresas.

\section{ABSTRACT}

The one-sided construction of informative economic agendas carried out by companies, by means of their interested promoters of facts and contents, could be the signal of a new phenomenon, here called corporate mediated com-munication. This could be regarded as similar to dis-information campaigns, but the objective now is to obtain from the public the most favorable perception according to the overall company interests.

\section{PALAVRAS-CHAVE (KEY-WORDS)}

- Comunicação corporativa (Corporate communication)

- Relações públicas (Public relations)

- Administração (Administration)

\section{Bárbara Délano Alfonso}

Prof. Prog. Comunicação Corporativa - PUC/Chile

\section{Paulina Gómez Lorenzini}

Prof. Faculdade de Comunicações - PUC/Chile

\section{Introduccion}

A mediados DE 1999, el Capítulo Chileno de la Asociación Interamericana de Periodistas de Economía y Finanzas -AIPEF-Chilesolicitó al Centro de Estudios de la Prensa de la Facultad de Comunicaciones de la Pontificia Universidad Católica de Chile, la realización de un estudio sobre la calidad de la información económica publicada por los media ${ }^{1}$ chilenos, impresos y de aparición cotidiana. Para ello, los investigadores abordaron un tema específico - la crisis eléctrica sufrida por el país - a lo largo de un período de dos semanas construidas.

Los resultados arrojados por dicho estudio $^{2}$ constataron empíricamente algunas hipótesis que la directiva de AIPEF - Chile se había planteado, tales como que durante el período de estudio existió "una visión periodística parcializada de la crisis", que restó atención "a temas que eran la principal preocupación de los lectores"3.

Al mismo tiempo la investigación verificó que en el caso de las noticias con énfasis económico, "cuando la empresa es el protagonista, su antagonista no siempre es explícito, lo que resulta en un desequilibrio de las posiciones". A ello se suma que "las fuentes informativas tienen una influencia directa y determinante en la pauta de los medios, según se desprende del alto porcentaje de noticias cuyo origen es formal y el también alto porcentaje 
de fuentes afiliadas o institucionales consultadas" y a que existe "una acentuada dependencia del periodista en las declaraciones de las fuentes, lo que le resta independencia o autoridad en el tema difundido"4.

Esta conclusión está avalada por el hecho de que del total de las fuentes consideradas por las noticias en estudio, el $62 \%$ era afiliada o institucional -esto es, representante de las empresas del área eléctrica-; el 17\% gubernamental; el $12 \%$ no identificada; y apenas el $7 \%$ independiente ${ }^{5}$.

Otras investigaciones prospectivas llevadas a cabo en la Escuela de Periodismo de la Universidad Católica ${ }^{6}$, coinciden con el estudio preparado para AIPEF-Chile respecto de la influencia de las empresas en el proceso informativo, tanto en la selección de las noticias (pauta) como en su producción (tratamiento otorgado al tema).

Más allá de quien esté elaborando técnicamente la pauta informativa, a partir de los datos significativos arrojados por este informe, se hace necesario reflexionar sobre los efectos que tiene para la sociedad y para las propias empresas -en su gestión de negocios-, el hecho de que ellas, como fuentes informativas, tengan una influencia tan directa y determinante en la agenda de los media. Al mismo tiempo se hace fundamental definir el tipo de fenómeno comunicacional al cual nos estamos enfrentando, pues aparentemente estaríamos ante una realidad que si bien no es nueva, no habría sido suficientemente distinguida de otras similares.

Desde el punto de vista del bien común, a la sociedad no le puede ser indiferente que las empresas no tengan suficiente contrapeso. La inquietud sobre quién y cómo se está construyendo la agenda noticiosa y determinando los contenidos a difundir por los media reviste alta trascendencia a partir de los impactos que este sesgo en la presentación de la realidad alcanza en y para la vida política, económica y social de toda comunidad.

En cuanto a las empresas, la eventual ganancia en imagen obtenida frente a los públicos a partir del ejercicio de una influencia unilateral en la agenda informativa puede transformarse en el largo plazo en una virtual 'espada de Damocles' para su legitimidad. La confianza y la credibilidad de los entornos constituyen un capital fundamental para desenvolverse con éxito en los exigente mercados actuales. $Y$ son precisamente estos los aspectos que resultarán más dañados una vez que al lector le sea evidente que el periodista y los media deben ser más que meros transmisores de la información que les proporcionan.

De ahí que a las universidades, a quienes compete la búsqueda y la comunicación de la verdad más allá de la técnica, la revisión crítica de esta situación, a la luz de la ética social, es una tarea ineludible. Entendido así, el presente trabajo busca clarificar cuál es el origen y la naturaleza del problema. Luego aclarar cuáles pueden ser las consecuencias de este aparente acierto de los relacionadores públicos en la vida social y en la propia gestión de las empresas, para avanzar a nivel exploratorio en la elaboración de propuestas que tiendan a determinar el papel que cabe a los comunicadores corporativos -como promotores intencionales de hechos y contenidos - en la solución de esta creciente transgresión.

\section{¿Comunicación Medial Corporativa?}

Al distinguir el accionar de las fuentes en el proceso de producción de la noticia económica, observamos que aparentemente no nos estamos enfrentando sólo a un fenómeno de desinformación tal como ha sido tradicionalmente definido, esto es "un conjunto organizado de engaños en una era en la que los medios de comunicación se hayan enormemente desarrollados", o frente a "la acción 
de inducir a error mediante el uso de informaciones falsas"8, sino más bien ante un fenómeno comunicacional más complejo y cuyo objeto es diferente.

La finalidad de esta acción comunicativa realizada por los actores económicos (las fuentes), a través de comunicadores corporativos, es tanto informativa como la de los periodistas, desinformativa como la de los propagandistas, persuasiva como la de los publicistas e inductiva como la de los relacionadores públicos. A ello cabe incluir además propósitos educativos y de omisión que se materializan tanto en función de los demás objetivos como por si mismos.

El elemento común que cruza transversalmente a cada una de estas actividades es la imagen de la empresa. Toda relación con los media está orientada a obtener de parte del público aquella percepción que sea más favorable para los intereses de las compañías. En sintonía con esta necesidad, se informa, se engaña, se seduce, se explica, se educa o se calla. El operador de todas estas acciones comunicativas continúa siendo el relacionador público, sea mediante departamentos o gabinetes internos (inoffice), o la contratación de agencias externas de comunicación.

Así, quiénes históricamente iniciaron su función en las organizaciones en términos de obtener buena voluntad (good will) o de desarrollar una estrategia de confianza y comprensión mutua ${ }^{9}$ con el público, hoy, tanto consciente como ingenua e incluso irresponsablemente, confunden y manipulan a la audiencia y al mediatizador a objeto de lograr aquella presentación y posterior lectura de los hechos que proteja sus errores y promueva sus hazañas, propiciando siempre una cobertura noticiosa en esencia parcial y por la cual está seguro que ningún lector estaría dispuesto a pagar, de saberlo.

Bajo la lógica de una extrema competitividad empresarial, un poder que fue entregado a los comunicadores de empresa para ser ejercido con estricto apego a la ética y al respeto por las personas y el bien común, es transgredido permanentemente. Si bien la responsabilidad de este fenómeno no es completa y absoluta de los comunicadores corporativos -hay alguien que hace y alguien que deja hacer-, en aquella parte que les compete hay una significativa evolución que realizar a objeto de no perder la confianza de la sociedad y el prestigio profesional. Como bien distingue Boiry ${ }^{10}$, no se ha de confundir el porvenir de las relaciones públicas consideradas como una función de la empresa con el de la profesión en sí. El futuro de esta última "reside en la aptitud de los profesionales para poder asumir -por el hecho de su competencia- mejor que nadie en la empresa, la responsabilidad de esta función que exige, como toda función de empresa, unos conocimientos específicos, pero que, sin duda y más que cualquier otra cosa, exige el respeto a una cierta ética".

\section{La noticia y la construccion de la agenda economica}

El establecimiento de un acontecimiento público depende de tres actores: los promotores de noticias (las fuentes); los recolectores de noticias (los periodistas) y los consumidores de noticias (Ia audiencia) ${ }^{11}$.

Atendiendo a las expectativas de los lectores y de la sociedad en su conjunto, y a la propia naturaleza de los medios de comunicación de masas en cuanto mediadores sociales, el proceso noticioso tiene dos objetivos fundamentales: responder a las necesidades informativas del público, entendidas éstas como "el conjunto de informaciones que precisa un ciudadano para desenvolverse con autonomía de juicio y libertad de acción en la sociedad en que vive"12, y satisfacer los requerimientos de la colectividad, la cual requiere que los media proporcionen 
cada día aquellos temas y hechos "que generan conexiones y refuerzan el sentido comunitario"13.

Este proceso informativo tiene como origen un acontecimiento o suceso que será valorizado o no como eventual noticia en función de su interés y su contribución para los individuos y la colectividad. Desde esta perspectiva, lo primero que pone en jaque al sistema informativo es la determinación de qué acontecimiento o suceso -mensaje recibido - amerita constituirse en noticia - mensaje emitido.

Asociándolos al quehacer periodístico, acontecimiento y suceso no son sinónimos, si bien ambos tienen iguales posibilidades de alcanzar el estatus de noticia en tanto conformen una ruptura de la lógica de lo cotidiano y esperable. La distinción radica en que mientras "los acontecimientos son tipos de variaciones perceptibles del entorno, que no han sido previstas por el ocupante del centro de ese entorno"14, los sucesos nos remiten a "convenciones sociales que han sido vulneradas"15.

De modo profesional o intuitivo, los relacionadores públicos se han convertido en eficientes productores de acontecimientos y sucesos, pseudo-eventos programados que "busca(n) fortalecer la imagen (de la empresa) a través de un acto"16.

Inauguraciones, seminarios, premiaciones, publicaciones, declaraciones, estadísticas, investigaciones, patrocinios, etc., se presentan diariamente a los media como acontecimientos susceptibles de convertirse en noticia, transformándose un simple dato en un "dato con impacto"17 y a una situación específicamente creada para los media "en algo improbable, singular y accidental"18.

Presionados por unas páginas a elaborar en tiempo restringido, los periodistas ceden a esta primera iniciativa de los comunicadores corporativos. No son los hechos sorpresivos o investigados en profundidad los que se imponen por su propio peso a la lógica noticiosa económica, sino aquellos seductoramente propuestos con antelación a través de agencias informativas, fax directos al periodista y llamados personales. Esta producción se lleva a efecto siguiendo la máxima descrita por Rodrigo, en cuanto a que "todo hecho social es potencialmente acontecimiento para los mass-media y toda noticia es potencialmente un acontecimiento para la sociedad". Se trata entonces, y en primera instancia, de entregar a los media aquella materia prima requerida para poder construir y transmitir "un producto que puede llegar a convertirse en acontecimiento social"19.

Para ello, los relacionadores públicos han escudriñado no sólo en las debilidades del periodismo sino también en las necesidades de la audiencia Si la mejor noticia es aquella que concentra el interés del mayor número de lectores, manejar los temarios del público es tarea imprescindible.

Así cada comunicador lleva a cabo su propia labor de reporteo interno y externo a objeto de determinar qué hechos de la empresa dicen relación con la pauta noticiosa de interés personal de los receptores, y en caso de no concordar, como presentar estos acontecimientos ante los media y el público de forma que sí lo aparenten.

\section{El subsidio informativo}

Como noticia es posible entender tanto todo"hecho verdadero, inédito o actual, de interés general que se comunica a un público que puede considerarse masivo, una vez que ha sido recogido, interpretado y valorado por los sujetos promotores que controlan el medio utilizado para la difusión"20, como aquella "representación social de la realidad cotidiana producida institucionalmente que se manifiesta en la construcción de un mundo posible"21.

Ambas definiciones, sin duda complementarias, dan cuenta de 
tres elementos fundamentales en la comprensión del concepto: que la noticia es todo hecho cierto y nuevo; que no es el hecho en sí mismo sino una representación social; y que la noticia es un producto fabricado por el media, a partir de la recolección, interpretación y valoración de dicho suceso y, podríamos agregar, sus circunstancias.

Cuidadosos de no vulnerar estos intereses periodísticos, los relacionadores públicos se han convertido en expertos facilitadores del trabajo informativo. Fruto de su propio conocimiento profesional o de su experiencia en los media -no hay que olvidar que numerosos comunicadores 0 directores de agencias de asesorías son periodistas-, así como de la formación entregada por la academia sobre cómo 'trabajar' con la prensa, éstos han aprendido exitosamente a construir noticias. Y a construirlas íntegramente.

La propuesta ya no se restringe a atraer la atención sobre el acontecimiento para propiciar su cobertura. Con amplio dominio de la lógica de los media, los contenidos son elaborados conforme a la estructura -encabezamiento, lead y cuerpo, el estilo, el lenguaje y los elementos de apoyo que cada uno requiere.

Concentrados además en captar al lector, cada mensaje está diseñado de modo de satisfacer esa pauta personal antes mencionada. Los hechos se organizan intentando dar respuesta a lo que es importante para cada lector en función de sus propios intereses - temario intrapersonal; con aquello que éste estima relevante para sus relaciones y diálogos con los otros - temario interpersonal; y finalmente con esos temas que corresponden al ámbito de la opinión pública y que dan cuenta no de lo que las personas creen trascendentes para sí o para tratar entre sí, sino de lo que piensan que los otros valoran como tal - temario de la percepción comunitaria (perceived community).

Incorporada, limitada o manipulada la perspectiva del media y del público, el comunicado de prensa, la declaración o la filtración que emana desde la empresa se revela atractivo, completo y escrito como por un periodista. Es decir, publicable.

Reproducible incluso sin mayores modificaciones. La búsqueda de la noticia y su modelación han quedado en manos de las fuentes. El subsidio informativo ${ }^{22}$ es total, pues ha faltado la recolección, interpretación y valoración de los acontecimientos por parte del periodista, así como su propia elaboración.

Pero esa es la intención, de que el mediador no medie o reduzca al mínimo dicha intervención, ya que en pos de ello se han generado con anterioridad relaciones y rutinas orientadas a establecer compromisos de beneficio mutuo que, por parte de la empresa, propenden siempre a condicionar el trabajo del periodista y a restringir la necesaria autonomía que éste precisa respecto de las fuentes para satisfacer las demandas del lector y de la opinión pública.

Por la vía de estas influencias priman los "condicionamientos en la entrega de informaciones a quienes no han sido dóciles en ocasiones anteriores" 23 y los obsequios, ofertas de viaje y cierta libertad de movimiento en el acceso a la empresa y a sus ejecutivos para quienes sí han entrando en el juego. De este modo, los sistemas de convivencia instaurados por los relacionadores públicos les permiten intervenir en el proceso noticioso incluso cuando la iniciativa es tomada por el medio.

Bajo esta dinámica, ciertos sectores y empresas "se van haciendo progresivamente intocables", "no pueden ser objeto de noticias que puedan acarrearles problemas" y se "tiende a llegar a una 'profunda comprensión' con la fuente, que en realidad no consiste más que en una identificación con sus motivos y métodos"24.

"Si en algún momento pudo hablarse de un periodismo más puro, significando con ese término un rol más importante del 
reportero o del reporteo, hoy el quehacer profesional de los periodistas aparece mucho más ligado a modos de hacer institucionalizados, ya sea en referencia a ambientes empresariales, institucionales o gubernamentales"25.

El resultado es percibido como todo un éxito por la alta dirección y el relacionador público, obviando así cualquier cuestionamiento en torno a las repercusiones que tiene para la capacidad de participación de los ciudadanos en la vida social el hecho de que quienes han puesto todo su esfuerzo por dominar el sistema informativo y limitar y parcializar la comprensión de la realidad, finalmente lo logren.

Calidad informativa y agenda

Todo proceso de producción noticiosa implica la planificación, selección y jerarquización por parte de los media de aquellos temas, acontecimientos y sucesos que ocuparán sus páginas cada día.

"Hay miles de maneras de construir una pauta, pero todas conllevan polémica. La valoración que cada medio efectúa de los aconteceres de la realidad y la intención de transmitir al público ese orden de importancia para que lo haga suyo (porque de eso se trata) supone, por un lado, seleccionar determinadas informaciones y excluir el resto, y, por el otro, jerarquizar las que han sido escogidas"26.

La agenda informativa que proponen diariamente los media a sus lectores determinará sobre qué cosas éstos hablarán, y, luego, sobre qué y cómo pensarán en torno a esas cosas ${ }^{27}$. Esta influencia decisiva de la agenda mediática sobre la agenda pública clarifica el interés de las fuentes por penetrar hasta lo más profundo de las redacciones -periodistaeditor-director- a fin de conquistar sus espacios y orientaciones.

Desde la perspectiva de la calidad informativa, esta agenda debiera ser el resultado de un contrato tácito entre el media y la audiencia. Y su principal indicador de verificación, la coherencia entre los requerimientos de los lectores y la oferta de los medios.

En esta visión cualitativa, el rol proactivo de las fuentes -en cualquiera de sus formas- es siempre percibido como una interferencia distorsionadora y manipuladora del sistema informativo, y uno de los más claros síntomas de que éste comienza a internarse en un proceso de abuso del poder delegado y, por tanto, de efectos corrosivos. En su sentido más estricto, la libertad de prensa es restringida cuando la evaluación de la noticiabilidad de los hechos está determinada más "por las actividades de una compleja burocracia diseñada para supervisar la red informativa" -frente a lo cual sólo ciertos acontecimientos excepcionales pueden imponerse-, que por la comunidad de intereses entre el media, su público y la sociedad $^{28}$.

Cuando esto acontece, estamos frente a lo que Tuchman denomina la "red de facticidad que se teje entre los que elaboran las noticias", la cual tiene por fin "crear una ilusión de credibilidad, pero que en la última instancia legitima el statu quo"29.

Por más que "la validez de las noticias acerca de ciertos sucesos puede ser negociada entre los miembros de las instituciones periodísticas y las organizaciones objeto de las informaciones" y que pragmáticamente ello resulta beneficioso para los media (por cuanto permite "a quienes elaboran las noticias trabajar con lo inesperado y producir una cantidad fija de noticias, independien temente de aquello que realmente ocurre, y dentro de los plazos relativos a los cierres de edición o a las limitaciones de presupuesto"30), siempre que ello acontece estamos frente a un problema que redituará en costos para la credibilidad y la confianza del público, fuente de la legitimación de los media en cuanto tales.

Para nadie es desconocida la envergadura de los problemas que en 
tal sentido ya tienen los media hoy en distintos países del mundo. Baste señalar que la Asociación Nacional de Editores de Estados Unidos (ASNE) se embarcó en 1998 en un estudio de tres años y con una inversión de un millón de dólares destinado a identificar y dar a conocer las causas de la desconfianza de las audiencias. Ese es el objetivo de su gran Proyecto de Credibilidad (Credibility Project).

¿Las razones? "Estamos perdiendo significativas dosis de confiabilidad, creo, no por lo que hacemos, por nuestro propósito - la mayor parte de la gente va a estar de acuerdo en que es un propósito importante- sino por la manera en que hacemos lo que decimos que estamos llamado a hacer"31, señala Jack Fuller ${ }^{32}$.

Ciertamente la calidad informativa, en términos de pluralidad, precisión, rigurosidad y veracidad en el establecimiento de la pauta y en el tratamiento de los temas, es el urgente desafío que tienen los media para recuperar su función social al interior de la sociedad. Y parte de la solución pasa porque a futuro los periodistas vuelvan a plantearse con más fuerza que nunca aquella pregunta que siempre ha sido fundamental en su relación profesional con los comunicadores corporativos: ¿cuál es el interés de la fuente al divulgar esta información?

\section{La agenda económica}

Antes de entrar al estudio de la realidad interna en que están insertos los relacionadores públicos y las presiones que enfrentan desde la alta dirección y desde la propia gestión de empresas y de su entorno para el establecimiento de un determinado tipo de relaciones con la prensa, es importante dilucidar qué está aconteciendo con la agenda económica y sus contenidos.

Según quien sea el observador del ámbito empresarial y de negocios que esté analizando la pauta económica de los media, el espacio destinado a las noticias del sector es excesiva o, por el contrario, insuficiente. No obstante, la jerarquización del tema económico en los media está siendo elaborada a partir de la importancia que efectivamente éstos y el público asignan a las noticias del sector.

Los resultados de los estudios realizados por Holli A. Semetko y Andreina Mandelli ${ }^{33}$ resultan extremadamente esclarecedores para confirmar esta visión. Las investigadoras señalan que en un esquema que contempla cinco ítemes: conflicto, economía, impacto humano, valores morales y excluidos (powerlessness), la economía para los media ocupa -en un ranking de uno a cincoel cuarto lugar, en tanto que para el público el mismo tema está en tercer lugar.

Deborah J. Blood y Peter C.B. Phillips $^{34}$ explican que las principales críticas que recibe el periodismo económico parten de tres supuestos. En primer lugar que la opinión de los media sobre la economía tiene un sesgo negativo; en segundo término que la cobertura de noticias económicas es capaz de hacer cambiar la percepción del público sobre la marcha de la economía nacional y, finalmente, que las noticias económicas negativas pueden influir por sí mismas en la economía y el panorama nacional.

Tomando todos estos elementos por verdaderos, Fred J. Evans sostiene que entre el mundo de los negocios y los media existen diferencias de fondo irreconciliables. Para este autor proveniente del ámbito de la gestión de empresas, si bien la cobertura de los temas económicos en la prensa ha crecido considerablemente, "ese grado de crecimiento ha generado polémica con la comunidad de negocios, ya que los ejecutivos consideran que dicha cobertura es superficial y sesgada", para luego agregar que "la evidencia demuestra el sesgo liberal y antinegocios de la prensa"35. Algo similar a lo pregonado por Herb Schmertz en su obra "El Silencio no es Rentable"36. 
El estudio sobre calidad informativa solicitado por AIPEF-Chile revela que en el caso chileno en materia de prensa económica, más que una gran disputa existe una cierta colusión entre media y empresas.

Si bien las fuentes se presentan reiteradamente disconformes con los contenidos de la información, las estadísticas demuestran que "al tratar las noticias con énfasis económico, hay menor presencia de antagonista", que "incluso cuando tiene un antagonista explícito se mantiene la preeminencia del uso de fuentes alineadas con el protagonista", "que la mayoría de los diarios hace escasa referencia a los consumidores como protagonistas", que existe un "excesivo uso de declaraciones de las fuentes", que "la diversidad de fuentes informativas se ve amenazada por la excesiva presencia de fuentes institucionales en desmedro de la consignación de fuentes independientes" y que existe "una clara tendencia al uso del canal formal como origen de la noticia"37.

Los resultados arrojados por este estudio coinciden con la percepción de Furio Colombo al respecto. "Se tiende a pensar que la noticia económica es objetiva y fiable. Está compuesta de datos que se pueden controlar. Sin embargo, precisamente en las noticias económicas se ocultan a veces pequeñas o grandes manipulaciones ajenas al periodismo. Con algún cómplice".

Agrega Colombo que "todo esto ha llevado a discutir acerca de la honestidad profesional (¿hay periodistas interesados personalmente en la buena imagen de una empresa y en la narración de los éxitos de esa empresa?), desplazando la alarma sobre unos casos que probablemente son escasos e insólitos y descuidando un motivo de alarma más profundo: noticias esenciales para la comprensión de la realidad - y muchas veces de las historias políticas- son ofrecidas de manera fragmentada, carente de verificación, carente de historia, subordinadas al ritmo y a la organización de los hechos establecidos por las oficinas de prensa, muchas veces influidas por la personalidad dominante de algunos grandes protagonistas"38.

"Las rutinas informativas generan, entre otros, dos tipos de problemas relativos a las fuentes. Uno tiene que ver con la rapidez - urgencia por salir al aire o despachar- que impide verificar completamente las informaciones entregadas por las fuentes. 'No hay tiempo' de comprobar lo señalado por la fuente, $y$, por la naturaleza de la información o por la calidad de la fuente, se termina confiando plenamente en ella, sin someterla a las verificaciones necesarias. Si el asunto trae consecuencias debidas a este exceso de confianza, se intenta siempre diluir las culpas entre las distintas instancias decisorias del medio, la urgencia de las condiciones de trabajo, etc."39.

Tagle insiste en que, por lo general, "se entiende el problema como superado cuando se ha establecido una relación duradera de confianza con algunas fuentes específicas, a las que se les otorga una garantía de calidad informativa casi a toda prueba. El otro (problema) tiene que ver con la necesidad de procurarse algún tipo de información, independientemente de la importancia o calidad de la misma y en directa dependencia de una fuente única".

La experiencia profesional nos ha permitido verificar que dentro del proceso noticioso, la influencia externa -de los promotores de información- es mayor en el proceso de acceso al circuito informativo -vínculo que se establece entre los relacionadores público y los reporteros- y va disminuyendo al entrar en el campo de la jerarquización -vínculo que se establece entre gerentes $y / 0$ directores de comunicaciones con editores de prensa, ya que cada vez van actuando dentro del media profesionales más alejados de las fuentes y más próximos a la empresa informativa. Pero, sin duda, son 
finalmente las fuentes -las empresasquienes terminan modelando la noticia, bajo el convencimiento de los hombres de negocios "que la información es demasiado poderosa para ser dejada a la sola apreciación de los periodistas"40.

Establecida por el marketing moderno la necesidad de las empresas de no ser sólo respetadas por el entorno, sino también de "hacerse amadas" por él, los altos ejecutivos han incorporado en sus filas a periodistas y relacionadores públicos "como defensa contra los contrapoderes nacidos de la sociedad civil". Su labor en este nuevo contexto es la de convencer al público - a través del media- de que en la medida en que lo conozcan y entiendan "gustarán más de mí"41.Es en este escenario de la empresa -fundamental para comprender los 'pecados' y desafíos de los relacionadores públicos- en el cual nos centraremos a continuación.

\section{Relaciones publicas y legitimidad}

En todo contexto democrático la comunicación es entendida como sinónimo de transparencia. $Y$, concordando con D'Humiéres, podemos señalar que bajo el efecto de este deseo de saberlo todo, las democracias han llegado a ser de alguna manera democracias de opinión ${ }^{42}$.

El devenir de la empresa, dentro de este contexto, no ha quedado sujeto sólo al parecer de clientes, accionistas, trabajadores y/o del Estado. Ha sido la sociedad, a través de los diferentes grupos de interés y de presión formados, y mediante los 'fenómenos de opinión' que éstos han suscitado, la que ha comenzado a cuestionar al sector empresarial.

Este cuestionamiento no se ha restringido exclusivamente a la calidad de los productos o servicios, a la rentabilidad de las acciones 0 al cumplimiento de la legislación vigente.

Han sido la naturaleza de su origen y desarrollo, la ética trasuntada por sus decisiones y comportamientos, la calidad de sus relaciones internas y externas, la seguridad de sus procesos, los beneficios y resguardos a los trabajadores, el impacto del medio ambiente... en definitiva, ha sido la legitimidad de su ser, quehacer y cómo hacer los que están siendo sometidos a juicio público.

La construcción de una imagen corporativa y de marca de alta notoriedad y fuerza concentra hoy los principales esfuerzos de la gran empresa. Enfrentada a un ambiente de negocios caracterizado por su globalidad, alta competitividad, complejidad y cambio permanente, ella ha centrado su confianza y quehacer en el direccionamiento estratégico $y$ en el marketing para asegurar un posicionamiento y una eficiencia que les permita mantener y acrecentar su posición en los mercados.

La vinculación entre la empresa y sus públicos ha quedado en este marco supeditada a una dinámica prioritariamente comercial, con la que se alinea instrumentalmente toda comunicación.

Las demandas por el ejercicio de una responsabilidad social por parte de las empresas, y que dan cuenta de su condición ciudadana (Corporate Citizenship), han suscitado conflictos de diversa magnitud en la relación empresapúblicos, especialmente debido a que las respuestas del sector empresarial se han producido más por el lado de las estrategias de imagen que de una comprensión de sus verdaderas responsabilidades frente a la comunidad y a la naturaleza de los lazos sociales que sostiene con ella ${ }^{43}$.

Esta posición se encuentra promovida por las enseñanzas y las orientaciones de algunas de las principales escuelas de administración, centros de estudio y revistas especializadas, quienes reducen la utilización de la comunicación institucional, corporativa o de relaciones públicas a una perspectiva mercadológica, supeditada al marketing y al megamarketing ${ }^{44}$.

Esta visión ha atentado contra la 
comprensión de las relaciones públicas según los postulados de Matrat ${ }^{45}$ quién establece como función principal de la disciplina aquella dirigida a crear, establecer, mantener o mejorar tanto la confianza y la comprensión mutua como el buen estado de las relaciones de las empresas y los diferentes públicos que condicionan su existencia y desarrollo.

$\mathrm{O}$ aquella de Simoes, que plantea las relaciones públicas como función política de la organización, responsable de la conciliación de los legítimos intereses de las empresas con sus públicos: "La actividad de Relaciones Públicas es la gestión de la función política de la organización"46.

\section{Política de comunicaciones y empresa}

"Estudios internos realizados por BursonMarsteller, investigaciones académicas y de revistas como Fortune, que edita cada año un especial sobre las compañías más prestigiosas en el ámbito internacional, demuestran que las empresas que activamente comunican y gestionan su reputación, tienen las marcas más fuertes, las mejores valorizaciones bursátiles, la mayor capacidad de atraer y retener a ejecutivos de mucho talento y la mayor capacidad de enfrentar momentos de crisis"47.

La relación entre imagen y rendimiento en el mundo de los negocios de hoy es determinante. La imagen, entendida como capital de confianza, constituye un valor agregado para la gestión, lo que se ha traducido en que dirigir sea sobre todo comunicar, y comunicar a un número cada vez mayor de audiencias internas y externas.

En este campo de las comunicaciones, los hombres de empresas presentan todavía un amplio abanico de debilidades. "Deberíamos admitir que, en la generalidad de los casos, somos realmente ignorantes en materia de comunicaciones. Pero para precisar aún más este concepto, quisiera distinguir entre ignorancia y ceguera. La ignorancia a que me estoy refiriendo tiene la virtud de abrir un mundo de posibilidades (...) de aprender. La ceguera, en cambio, desde el momento en que creo saber, no me permite recapacitar, no me constriñe a aprender"48.

El primer efecto de esta ceguera o ignorancia percibida entre los ejecutivos consiste en la convicción de que las comunicaciones son un tema altamente opinable.

Cuando al interior de los directorios de las empresas se discuten los temas relativos a inversiones, son los expertos quienes se enfrentan, discuten y deciden sobre la base de cifras, proyecciones y tasas de retorno. Mas cuando la toma de decisiones es referente al plan de comunicaciones, son las subjetividades las que asoman y se confrontan a partir de experiencias personales, consejos de amigos e historias de otras compañías, incluso absolutamente ajenas al giro del negocio. Las sesiones pueden así durar horas, sin llegar a acuerdos ni considerar la opinión de los realmente expertos.

La segunda consecuencia dice relación con la búsqueda del bajo o alto perfil por sí mismo.

Desde el punto de vista económico, la justificación del bajo perfil tiene siempre la garantía de ser más barato en tiempos de paz. Sin embargo, este gasto considerado excesivo e innecesario, cuando arrecia la crisis suele tornarse una inversión indispensable y con recursos ilimitados, creyendo ilusamente que una buena reputación y la credibilidad que ella conlleva pueden construirse en cosa de días.

Sin embargo, más allá de las razones financieras, la opción por el bajo perfil suele ser mayoritaria de aquellos ejecutivos 'anti media' per-se, quienes aún no han tomado conciencia que fruto de las grandes transformaciones tecnológicas, del auge de las redes de comunicaciones y de la creciente búsqueda de transparencia por parte del público, el espacio privado de las 
empresas se ha ido reduciendo ${ }^{49}$.

Asimismo, esta postura anti media es compartida por quienes han tenido en el pasado experiencias calificadas como desastrosas con la prensa.

El alto perfil, por su parte, se caracteriza por un abuso de las comunicaciones, que induce a la exigencia de una presencia permanente en los media, independientemente del valor noticioso de las informaciones a proveer. La comunicación se transforma en un fin y no en un medio al servicio de la estrategia de la empresa.

Esta avalancha informativa responde al interés por dar notoriedad y fuerza a la imagen de la empresa. Pero esta política suele implantarse también por aspiraciones asentadas en debilidades más humanas: la de las vanidades personales, que no dejan de estar presentes cuando se trata de aparecer en los media. "Poquísimas veces, en el periodismo mundial, la noticia económica viaja separada de un rostro, de un perfil, de la imagen de alguien que domina un sector financiero productivo o distributivo. Es decir, nos hallamos ante un relato novelado de la economía contemporánea, que lectores y espectadores están invitados a vivir siguiendo las aventuras del gran protagonista de la hazaña, una especie de nuevo héroe que compite de cerca con los líderes políticos elegidos y con unos pocos héroes más del mismo calibre"50.

El gran riesgo de esta excesiva exposición es que "el tránsito de héroe a villano puede ser meteórico". "Los medios de comunicación (sobre todo la televisión) encumbran y/o fulminan a una velocidad de vértigo. Engullen en cuestión de horas a personajes que han divinizado durante años"51.

Ambas posturas tienen la deficiencia de generar políticas de comunicación autorreferentes, que omiten la necesaria y equilibrada integración que la empresa debe sostener en cada momento con su entorno, en función de las características particulares que éste presenta y de la posición relativa que se desea ocupar dentro de él.

La pregunta adecuada en comunicaciones es aquella que está centrada en el perfil correcto. Esto exige, sin duda, un planteamiento y una respuesta estratégicos, cuya base es la identidad de la empresa. La comunicación es un instrumento al servicio de la imagen, una imagen deseada que se aspira legítimamente a alcanzar en tanto exista una coherencia real entre lo que se dice, se es y se hace, y las demandas de los públicos y la sociedad.

Para que ello logre materializarse, "es necesario que directivos y ejecutivos se tomen la comunicación en serio, igualándola a la investigación o a la dirección financiera, es decir, tratando(la) de manera profesional y en profundidad. Cuando se habla de comunicación, se habla de diálogo. Pero hay más. Es necesario, de manera imperiosa, que las informaciones difundidas por el público sean para la empresa tan importantes como las que ella misma difunde. En efecto, el público difunde permanentemente, de manera explícita o no, mensajes que deben ser captados para poder tenerlos en cuenta de manera eficaz en nuestras acciones de comunicación y para poderlos integrar a nuestras decisiones"52.

Boyd agrega que "la comunicación es un elemento esencial y constituye el proceso que, a través de las decisiones cotidianas, hace cualquier empresa bien o mal dirigida. Los efectos de una nointegración de la comunicación en el proceso de gestión no se perciben tan rápidamente como los provocados por un retraso técnico o una gestión financiera inadecuada. Pero, a la larga, paralizan a la empresa. Una mala política de comunicación resta parte de eficacia a una buena decisión".

Relaciones públicas y comunicación 
"Las relaciones públicas son, en primer lugar, una manera de comportarse $y$, secundariamente, una manera de informar, de comunicar con la intención de establecer y de mantener relaciones de confianza basadas en un conocimiento y una comprensión mutua entre el grupo, considerado en sus diferentes funciones y actividades, y los públicos que le conciernen, por una u otras de estas funciones o actividades". "Las relaciones públicas implican la puesta en marcha de una política de comunicación consciente, organizada, sistemática y continuada"53.

A esta definición, Simoes agrega que "la finalidad última (o primera) de las relaciones públicas es, a través de la legitimación de su autoridad, de su poder de decisión, influir en los mercados para iniciar, expandir y mantener los intercambios con la organización a fin de mantener su existencia"54.

Así entendido, el objeto principal de las relaciones públicas es el proyecto empresarial y su articulación e integración con las necesidades e intereses de los individuos y de la sociedad. En pos de ello se transmite la finalidad y el espíritu que anima a la empresa, los principios y valores que la rigen, las competencias con las cuales lleva a cabo su misión y las contribuciones o el valor que genera al bienestar de sus clientes, inversionistas, recursos humanos y la comunidad. El propósito de esta comunicación es legitimar a la organización, vale decir, "crear una disposición generalizada (en sus públicos) para aceptar decisiones de contenido aún no definido, dentro de ciertos límites" 55 .

Esta legitimación bien puede alcanzarse por la adecuación del ser y de las actuaciones de la empresa a un orden trascendente (divino, natural o histórico) o a consensos sociales, donde la diferencia entre lo legítimo y lo ilegítimo dependerá "de la comunidad de creencias en la que se sitúa el (o los) sujeto(s) que juzga(n)"56.

Esta exigencia de legitimidad hacia las organizaciones no les es exclusiva. El requerimiento es igualmente válido para las personas y para todo tipo de entidad: gobierno, sindicatos, grupos profesionales, confesiones religiosas $y$, por cierto, los negocios corporativos cuya historia está marcada por hechos que dan cuenta de un acento preferencial y a veces excluyente por los beneficios propios, en desmedro de los comunitarios.

La legitimidad, por tanto, constituye un atributo a conquistar a partir de una realidad interna que se expresa en un comportamiento que es considerado como justo por quienes lo sufren u observan.

Esta legitimidad es la base más sólida para la construcción de una buena reputación por parte de la empresa, entendida ésta como la percepción y opinión positiva de los públicos en torno a ella, lo que le confiere credibilidad y confianza y, como consecuencia, una disposición favorable de todos los actores sociales hacia su actuación, permanencia y crecimiento institucional.

Situado bajo estas fronteras, el trabajo del relacionador público o de los gabinetes de comunicación ${ }^{57}$ frente a los media tienen por propósito interpretar a la organización ante el público, buscando -a partir de la comprensión y/o adhesión de las personas y de la sociedad a su proyecto empresarial, la legitimidad y reputación requeridas a objeto que sus ámbitos de libertad y poder no sean restringidos ${ }^{58}$.

En palabras de Drucker, "La organización moderna tiene y debe tener poder social, y mucho. Necesita poder para tomar decisiones sobre las personas,(...) para fijar las reglas y las disciplinas necesarias para producir resultados,(...) poder para decidir qué fábricas construir y dónde y qué fábricas cerrar. Necesitan poder para determinar los precios y así sucesivamente".

Cuando los consensos sociales se articulan en contra de la empresa, la opinión pública suele presionar al poder político para que intervenga en los 
diferentes mercados (social, financiero, laboral, etc.), con nuevas regulaciones, fiscalizaciones y limitaciones, que no vienen sino a transformar aquello considerado por la sociedad como ilegítimo en ilegal.

Los periodistas, en su rol de mediatizadores de la realidad de la empresa, debido a una formación no especializada y a que cubren el campo informativo económico superficialmente y muchas veces sin dimensionar los efectos que sus publicaciones pueden alcanzar a nivel de la generación de decisiones y comportamientos en actores determinantes para la vida de la empresa, inadvertidamente suelen suscitar percepciones trascendentes, que influyen en la marcha de la economía y en oportunidades alcanzan consecuencias devastadoras para la buena reputación de las compañías e incluso para sus resultados en términos de negocios.

A la inversa del esfuerzo que han realizado los relacionadores públicos por comprender y utilizar la lógica de los media, a objeto de tomar medidas de seguridad y cautelar los intereses de la empresa, con lo positivo y negativo que ello conlleva, los periodistas no han entrado en la lógica empresarial y, aún más, le tienen temor a comprender su dinámica creyendo equívocamente que ello en vez de otorgarles rigurosidad en el ejercicio de su trabajo los podría convertir en cómplices del sector empresarial.

Las condenas de las fuentes sobre la calidad de la cobertura informativa de los temas económicos, en términos de falta de profundidad, contexto, análisis y proyección, ha llevado frecuentemente a los ejecutivos a considerar su intervención en el sistema medial como fundamental para la adecuada educación e información del público y la salvaguarda de sus esfuerzos e inversiones en gestión e imagen, convencidos que a lo más el reportero será capaz de descubrir 'que algo pasa', pero raras veces 'qué es lo que pasa', por tanto lo mejor es confiarle "al periodista sólo una eficiente labor de mensajero, que viene, graba, recoge información impresa y se va"59.

\section{El poder economica y los media}

"Los desvíos éticos en relaciones públicas se encuadran en dos situaciones. Se localizan a nivel de función organizacional, cuando decisiones conscientes e intencionadas, tomadas por la cadena de mando, presuponen acciones y resultados perjudiciales a los derechos de los públicos, ocasión en que el bien común es pasado a llevar y la legitimidad es olvidada. (...) La otra situación es cuando el profesional manipula a los públicos por medio de los instrumentos de comunicación, mintiendo, suprimiendo parte o todos los hechos 0 , aún más, asentándolos para (enfrentar) futuras posiciones desfavorables"60.

Ante estos hechos y sus repercusiones en los media y en el público, Foucault ${ }^{61}$ reconoce: "estamos sometidos a la producción de la verdad desde el poder", preguntándose luego: “¿qué tipo de poder es susceptible de producir discursos de verdad que están, en una sociedad como la nuestra, dotados de efectos tan poderosos?".

La respuesta tiene, sin duda, al menos dos variantes diferentes del poder, el político y el económico. Visto así, el tema del poder en la construcción de la agenda pública no es menor y por ello es preciso entrar en su análisis.

Siguiendo a Foucault, frente al fenómeno de comunicación medial corporativa se trataría de distinguir entre quienes ejercen el poder de saber la verdad y quienes ejercen el poder de difundirla, y observar sus consecuencias en una sociedad altamente mediatizada.

Escudriñando más allá este pensamiento en torno al poder, es posible observar que, entre otros planteamientos, el autor sostiene que el poder "no es un atributo como la riqueza o un bien. El poder funciona, se ejercita a través de una 
organización reticular... el poder transita transversalmente, no está quieto en los individuos... no es algo dividido entre los que lo poseen, los que lo detentan exclusivamente y los que no lo tienen y lo soportan"62.

Por ello no es factible analizar el poder deduciendo un avance desde un presunto centro hacia donde se prolonga, en otras palabras, hacia abajo, o hacia lo más molecular de la sociedad, sino que por el contrario, el poder debe ser sujeto de un análisis ascendente: "arrancar de los mecanismos infinitesimales, que tienen su propia historia, su propio trayecto, su propia técnica y táctica, y ver después como estos mecanismos de poder han sido y todavía están investidos, colonizados, utilizados, doblegados, transformados, desplazados, extendidos, etc., por mecanismos más generales y por formas de dominación global".

Profundizando en el concepto, Foucault añade que "no es la dominación global la que se pluraliza y repercute hacia abajo; pienso que hay que analizar la manera como los fenómenos, las técnicas, los procedimientos de poder funcionan en los niveles más bajos, mostrar como estos procedimientos se desplazan, se extienden, se modifican, pero sobre todo como son investidos y anexionados por fenómenos más globales y como poderes más generales o beneficios económicos pueden insertarse en el juego de estas tecnologías al mismo tiempo relativamente autónomas e infinitesimales del poder".

Finalmente acota que "la teoría de la soberanía (que) permite fundar un poder absoluto en el dispendio absoluto del poder, no permite por el contrario calcular el poder con un mínimo de dispendio y un máximo de eficacia" 63 .

Analizado el objeto de nuestro estudio desde esta perspectiva, es posible observar que la masificación de los media y la profesionalización de los comunicadores corporativos puede estar tendiendo a sostener en un lugar de privilegio a quienes detentan el poder económico, el poder de saber la verdad de lo que acontece en su interior y el poder de resguardarla mediante el acceso restringido a la información, lo que permite confirmar o cuestionar lo señalado por el discurso oficial, en desmedro de quienes tiene el deber de averiguarla y difundirla al público para que éste logre una toma de decisión calificada y una activa participación en la vida social.

Más aún, esa profesionalización, unida al auge mediático, pueden estar contribuyendo a que el sector empresarial pueda cumplir sus metas comunicacionales con un mínimo de dispendio y un máximo de eficacia en el ejercicio de su poder, inde pendientemente del grado de verdad de la información que proporciona a través del relacionador público a los media.

Así, mediante el monopolio del conocimiento sobre sí, el control sobre las iniciativas de los acontecimientos y sucesos que serán noticia en torno a la empresa, del dominio de la lógica mediática y de la representación social de los hechos, del uso frecuente de rutinas y prácticas orientadas a seducir al reportero e identificarlo con sus fines y métodos, y de las restricciones impuestas al libre acceso a la información interna, se estaría ofreciendo a los hombres de negocios la posibilidad casi cierta de contar con un poder que ya no transita, sino que permanece casi en calidad de atributo o de bien de la propia empresa.

Cuando la imagen social de las organizaciones tenía una baja trascendencia en la determinación de sus resultados, el ambiente medial tendía a ser hostil hacia el mundo de los negocios y las ideologías importaban más que las cuestiones económicas, existían restricciones provenientes del propio entorno que promovían la regulación del sistema.

Pero cuando la información es una apuesta, un elemento de poder que se ejerce o se busca ejercer por exclusión, de 
modo de favorecer el logro de imágenes más destacadas y de posiciones de liderazgo frente a los demás; cuando las organizaciones intermedias son incipientes y los ejecutivos irresponsables salen impunes de sus actos, mientras quienes actúan con responsabilidad no son lo suficientemente recompensados; cuando los objetivos comerciales de los media presionan fuertemente sobre su rol social, la libertad del sistema informativo para llevar adelante sus funciones de consenso, vigilancia e información tiene pocas oportunidades de imponerse, amenazándose con ello también las demás libertades de los ciudadanos.

Cuando el sistema es instrumentalizado y el público desconoce esa evidencia, es su propia opacidad lo que la conducirá a su decadencia, pues las tentaciones de los actores detentores del poder siempre presionarán a los media para ir un paso más allá, hasta llegar a poner en peligro aquello que asegura su capacidad de funcionamiento: la credibilidad del público.

Juegos peligrosos en la relación empresamedia

Frente a todo lo señalado, ¿qué podría decirse que es lo que legitima la vinculación empresa/media o fuente/periodista? Desde el punto de vista del lector "sin duda, los resultados. Es decir, si el fruto de esa relación es una información de mejor calidad, una información pertinente que le permite acceder a un conocimiento más completo y riguroso de la realidad" 64 .

¿Permite la actual vinculación asegurar tales resultados? "Un análisis preliminar en torno a la naturaleza y función asignada a ambos oficios conduce en principio a negar tales efectos. En tanto el propósito fundamental de los medios es entregar una información lo más completa e imparcial, objetiva en torno a hechos noticiosos, a los departamentos de comunicación se les ha asignado -por gran parte de la literatura especializada y por cierto de la alta dirección- la función de velar porque la empresa obtenga por parte de los medios la mejor cobertura a sus actividades y propuestas, entendiendo por tales la más amplia y favorable posible a sus intereses e imagen pública"65

Esta relación que en principio se observa como de suyo ilegítima entre organizaciones y media, puede ser legitima en su forma y fondo en la medida en que todos los integrantes del proceso informativo tomen conciencia y asuman su responsabilidad frente a quienes en definitiva le pueden y deben demandar un producto de calidad: los lectores, desde la perspectiva individual, y la sociedad, desde la perspectiva del bien común.

Siguiendo a Drucker ${ }^{66}$ es posible convenir que la primera responsabilidad social de las empresas $-y$ en esto caben tanto las empresas periodísticas como aquellas que se constituyen en sus fuenteses hacer bien su trabajo. En segundo lugar, son responsables de su impacto sobre las personas, la comunidad y la sociedad en general. $Y$, finalmente, las compañías actúan de modo irresponsable cuando van más allá de lo necesario para realizar su tarea.

Esta visión implica que las organizaciones deben responsabilizarse de los límites de su poder, esto es del punto en el cual deja de ser legítimo el ejercicio de sus funciones, "pues el poder, sin responsabilidad, degenera en una falta de resultados y las organizaciones deben rendir"67.

Esta posición, sin embargo, no es la única sobre la materia. Brummer 68 da cuenta de que lo que realmente exigen los accionistas de las empresas es el logro de resultados económicos efectivos, los que deben alcanzarse de acuerdo a las leyes del lugar en que se está operando, estándoles impedido realizar fraudes o estafas, pero que más allá de eso tanto CEO's como PAE's no tienen mayores 
responsabilidades.

Este es el escenario en que se enfrentan periodistas y relacionadores públicos, presionados por diversas ópticas y opciones, usando un mismo campo de batalla: los media.

Los media deben vender el máximo posible de ejemplares y atraer el mayor número de lectores o de audiencia para lograr el mayor valor de sus centímetros o segundos de emisión en el mercado de los avisadores así como para ejercer influencia en esferas del poder político y social. Las empresas no periodísticas, en tanto, están obligadas a obtener sus metas comunicacionales con el mínimo dispendio de esfuerzos.

Ambos tienen objetivos que cumplir y que no van a lograr sin la colaboración mutua. Se necesitan, independientemente de que gusten o no el uno del otro.

En tanto las empresas periodísticas requieren los recursos económicos provenientes de la publicación de avisaje o a través de la venta de la divulgación de hechos noticiosos que acontecen al interior de las organizaciones, las empresas no periodísticas necesitan a su vez vehiculizar sus avisos a través de los media y requieren que sus hechos positivos sean ampliamente conocidos por el público, al tiempo que sus hechos vergonzosos sean mantenidos en sigilo o, si ello no es posible, al menos que sean aceptados por la opinión pública como un percance lamentable y no como una situación fruto de una política organizacional.

Mientras ambos colosos se enfrentan, se cortejan y negocian, el público debe entrar necesariamente, si quiere vivir informado, en un juego peligroso para sus intereses: creer lo dicho por el media, que hoy no vendría a ser otra cosa que creer lo que la fuente le ha dicho al periodista.

Ante la creciente amplitud de intereses y la multiplicidad de fuentes disponibles para cada uno de los temas de su interés, al lector o auditor le resulta imposible prescindir de los media, ya que lograr el acceso directo a las fuentes le sería una tarea físicamente imposible. Ahora bien, tampoco está en condiciones de cotejar o verificar todas las noticias que le entrega el media elegido por él, de modo que no tiene sino la posibilidad de establecer una relación fiduciaria con éste. Tiene imperativamente que hacer fe en que el media -"su" media- está citando a todas las fuentes disponibles, dándole la opción de comprender el hecho narrado con todas sus aristas e implicancias. No puede poner en duda la calidad informativa del media en el cual ha depositado su credibilidad.

Cuando el grado de vinculación entre la fuente y el media es muy alto y el lector percibe ese compromiso espurio -que le deja de lado en su rol protagónico y que le afecta en su toma de decisiones cotidiana, es posible que en un primer momento busque un media alternativo.

Si el fenómeno se repite, es esperable que pase a leer o escuchar a todos los media con un cierto grado de excepticismo y comenzará a buscar fuentes alternativas, desechando todo aquello que le huela a noticia institucional, finalizando en una desconfianza y cuestionamiento por principio a las informaciones de economía y negocios. Así, para las empresas tener manejados a los media podría pasar de ser un excelente negocio a un gran problema.

\section{A modo de conclusiones preliminares}

Durante las últimas décadas, las fuentes económicas, en su calidad de promotores intencionales de noticias, han conquistado un espacio cada vez más significativo en los media. ¿Por qué podrían o deberían cederlo voluntaria y gratuitamente, cuando ello sirve a sus intereses sin infringir la ley?

Hasta ahora, la sociedad ha atribuido casi exclusiva y excluyentemente a los periodistas y a los media, la responsabilidad por la construcción de una agenda informativa de calidad. Los costos por los errores y las deficiencias en el logro 
de tal objetivo, han recaído por ende en ellos, con el consecuente desprestigio y desvalorización social de la profesión y de la industria informativa.

La incapacidad de los lectores por descubrir el verdadero rol que juegan las fuentes en la determinación de los temas de la agenda y del contenido de las noticias ha mantenido hasta ahora a las empresas al margen de la polémica.

Los efectos tanto positivos como manipulativos de sus acciones comunicativas de orden informativo, desinformativo, persuasivo, inductivo, educativo y de omisión, llevadas a cabo por intermedio de relacionadores públicos, aún no han sido percibidos nítidamente.

No obstante, el sostenido mejoramiento del nivel educacional de la población en términos generales y particularmente en materias económicas y financieras, así como su mayor conocimiento y comprensión del funcionamiento de los media y de las empresas, el proceso de globalización cultural y comercial, el poder derivado de su creciente capacidad adquisitiva y finalmente de su condición de consumidor, le están llevando a preguntarse con un mayor grado de profundidad y suspicacia la intencionalidad que esconden las fuentes al divulgar sus informaciones y la relación de interdependencia, colusión o de dominación que éstas ejercen sobre los media más allá de lo razonable y esperable en función de su comunión de intereses.

La parcialidad y la negligencia observadas por el público en la cobertura de prensa de la realidad empresarial y su consecuente incongruencia con los problemas e insatisfacciones que los lectores experimentan como trabajadores, clientes y/o miembros de una comunidad en sus vinculaciones con las empresas - en las que se revela con contundencia el poder fáctico que ellas ejercen como consecuencia de su tamaño, riqueza e influencia en otros ámbitos de la sociedad-, está generando en diferentes sectores de la población un sentimiento anti-empresa que desde ya está obstaculizando inversiones, boicoteando productos, favoreciendo sanciones y legislaciones restrictivas, y promoviendo a los grupos de interés y presión que se oponen al mundo de los negocios.

Las razones que conducen a este apoyo público dicen relación cada vez más con la necesidad de las personas de que algo o alguien ponga límites a este poder incontrarrestable que se cree y afirma que están ejerciendo las empresas, que con una verdadera solidaridad para con cada una de dichas causas.

En este sentido, los hombres de negocios no se han hecho cargo aún de una realidad que los trasciende, cual es que "con frecuencia el ser humano no actúa como maximizador racional de la utilidad, en el sentido estrecho del término utilidad, sino que inviste a la actividad económica de muchos valores morales tomados de su vida social"69.

El ámbito económico no está regido por sus propias leyes. Requiere de una sociedad civil fuerte y dinámica que garantice su vitalidad ${ }^{70}$. La actividad económica está inexorablemente ligada a la vida política y social, requiere de la colaboración y la participación de los otros. Por lo mismo, la pérdida de la confianza pública en las empresas puede alcanzar insospechables repercusiones no sólo para su crecimiento y desarrollo sino para la calidad de la convivencia al interior de la sociedad.

"La gente que no confía en su prójimo termina cooperando con éste sólo bajo un sistema de normas y regulaciones que tienen que ser negociadas, acordadas, litigadas e implementadas, a veces en forma coercitiva. Este aparato legal que sirve como sustituto de la confianza, contiene lo que los economistas denominan 'costos de transacción'. En otras palabras, la desconfianza ampliamente difundida en una sociedad impone una especie de impuesto a todas las formas de actividad 
económica, un impuesto que no tienen que pagar las sociedades con un alto nivel de confianza interna"71.

"En un sistema social, la confianza es el lubricante básico y muy eficiente (...) Desafortunadamente, no es un bien que se pueda comprar con mucha facilidad. La confianza y sus valores afines, como la lealtad y la veracidad (...) incrementan la eficiencia del sistema (...) Pero su comercialización en el mercado es técnicamente imposible y carente de significado"72.

Visto así el fenómeno, no se trata de pensar que su análisis es importante sólo desde la perspectiva de la reputación o el reconocimiento de las empresas. Los efectos son muchos más vastos y trascendentes en términos de la verdadera libertad económica y de prensa de que goza la sociedad y del capital de confianza con que ella cuenta para avanzar en su desarrollo.

Por lo mismo urge el estudio y la reflexión en torno a lo que se está haciendo, cómo se está haciendo y a los impactos que estos tienen para el futuro de cada uno de sus actores. La gran pregunta que corresponde formularse, es ¿En qué punto el bien de una organización se convierte en un mal social ? $^{73}$.

Una respuesta desde la etica y la responsabilidad

El avance en la resolución del problema que nos plantea el fenómeno de la comunicación medial corporativa exige traspasar los límites del derecho, pues el hecho de que las acciones emprendidas de modo articulado, sistemático y con una toma de decisiones planificada sean judicialmente defendibles y absueltas, no significa que éticamente también lo sean.

Ciertamente no se trata aquí de pregonar por una independencia absoluta entre el mundo económico y los media. Esta independencia no puede existir; sus interrelaciones son claras.

Se trata más bien de modificar la óptica bajo la cual el sector empresarial se inserta en la sociedad y actúa frente a los media, pasando del habitual referente ' ¿a qué tengo derecho?', cuyas respuestas suelen encontrarse en las leyes inexorables de la competitividad y del mercado, a una visión más contribuyente del sistema: '¿de qué soy responsable?'74.

En este contexto, el relacionador público debe dejar de condescender con la tentación y la función muchas veces asignada de 'manejar' a la prensa, la que además de reprobable encierra la peligrosa posibilidad de una contrarreacción por parte de periodistas y media de querer 'manipularlo' a él y al sector empresarial, convirtiendo a consumidores, ecologistas y autoridades fiscalizadoras en protagonistas decisivos de las noticias.

El atractivo beneficio que el ser militantemente anti-empresas puede suscitar en términos de incremento de los índices de lectura, puede no volver tan impredecible esta actitud. Este camino hacia un rol más consciente y responsable de las empresas hacia los media no está ajeno de peligros para el relacionador público.

Frente a una visión pragmática ante el tema por parte de los ejecutivos, y a un posicionamiento no del todo claro y seguro de la función política en cuanto integración y no imposición (vía seducción, desinformación u omisión) de intereses al interior de las organizaciones, ¿no se les estará quitando la plataforma más valorada para su gestión?. ¿Qué beneficios concretos podría reportarle la modificación de sus comportamientos, ya no desde una perspectiva de rehuir a futuros males, sino de ganancia o utilidad para él mismo?

Mientras la valía de las relaciones públicas radique de modo importante en su capacidad para traspasar más allá de lo "justo, lícito, genuino y verdadero en cualquier línea"75 la cobertura de prensa que las compañías ameritan en función a su 
realidad y contribuciones, su posición en la empresa será siempre débil e inestable.

El comunicador corporativo no puede olvidar que dispone de un enorme bagaje de otros instrumentos que le permiten dosificar su presencia en los media y no volcarse con exclusividad a ellos. Sin duda ninguno de estos otros instrumentos alcanzará el mismo impacto en la opinión pública, pero ¿es que la empresa requiere para su efectiva gestión de negocios que la mayor parte de sus hechos lo obtengan?

Desde su inicio, el objetivo de este ensayo ha sido el de presentar y describir un fenómeno que hemos denominado comunicación medial corporativa, a fin de reflexionar sobre una intervención que se ha hecho habitual por parte de las empresas en los media y que livianamente se ejerce visualizando sólo los efectos de imagen que ello reporta a la empresa.

La madurez que han alcanzado en materia de desarrollo social y de gestión de negocios los países latinoamericanos, entre ellos Chile, obliga a plantearse esta problemática desde una perspectiva más global, y que cuestiona la actuación que cada uno de los actores que promueven o permiten, con la acción, la indiferencia o la inmovilidad, su mantención. Dentro de estos actores ocupan un papel trascendental las universidades, quienes forman técnica y actitudinalmente a ejecutivos, periodistas y relacionadores públicos.

Las distintas visiones, especialmente éticas, con las cuales se aborda esta educación, así como la parcialidad con que se enfrentan sus conocimientos -pro negocios, pro sociedad, pro media per se-, están afectando la comprensión integral de la problemática comunicacional corporativa. Por lo mismo, la intervención de las universidades, en términos de reflexión, investigación y análisis de casos, con las consecuentes propuestas como fruto de la revisión y del juicio crítico, riguroso y profundo aplicados sobre esta realidad, se hace insoslayable.

Saber cómo se hace una infinidad de cosas, no es lo mismo que saber cómo actuar con ellas. Este es el enorme desafío al que es preciso dar respuesta desde una mirada integradora e integrada .

\section{Notas}

1 Las autoras usarán el término media para referirse, a lo largo del ensayo, a los medios de comunicación de masas de libre recepción 0 adquisición, excluyendo a los medios técnicos, de alta segmentación 0 de origen empresarial que son distribuidos gratuitamente 0 que pueden ser adquiridos exclusivamente por suscripción.

2 Alessandri, Francisca, Edwards, Cristóbal y Porath, William, Estudio de calidad informativa, Centro de Estudios de la Prensa, Facultad de Comunicaciones, Pontificia Universidad Católica de Chile, Santiago, 1999.

3 Ibid., p. 16.

4 Ibid. , p. 40.

5 lbid., p. 16.

6 Cf. Pellegrini, Silvia, "Medición de la calidad de la prensa en Chile", Cuadernos de Información №13, Escuela de Periodismo Pontificia Universidad Católica de Chile, Santiago, 1999, pp. 49-55 y Peralta, Javier, "Diarios de información económica: la diferencia existe", Cuadernos de Información №10, Escuela de Periodismo, Pontificia Universidad Católica de Chile, Santiago, 1995, pp. 34-48.

7 Durandin, Guy, La información, la desinformación y la realidad, Paidós, Comunicación/69, Barcelona, 1995.

8 Ibid., p. 21, citando al Diccionario de la Lengua Rusa, de S. Ojegov, 1949 (dezinformatsia).

9 Cf. Boiry, Philippe A., Les relations publiques ou la stratégie de la confiance, Eyrolles, Paris, 1989.

10 Boiry, Philippe A., en versión española, Las relaciones públicas o la estrategia de la confianza, Gestión 2000, Barcelona, 1998, p. 107.

11 Rodrigo Alsina, Miquel, La construcción de la noticia, Paidós, Comunicación, Barcelona, 1996, p.113. 
12 De Fontcuberta, Mar, "Pauta y calidad informativa", Cuadernos de Información №13, Escuela de Periodismo, Pontificia Universidad Católica de Chile, Santiago, 1999, pp. 61-69.

13 Rozas, Eliana, "La selección noticiosa, entre la importancia y el interés", Cuadernos de Información №12, Escuela de Periodismo, Pontificia Universidad Católica de Chile, Santiago, 1997, pp. 20-25.

14 Moles A., "Notes pour une typologie des événements", Communications №18, citado por Rodrigo, p. 93.

15 Ibid. , Rodrigo, p. 93.

16 Ponte Pierre, Francisco E., "O Relações Públicas como intelectual: considerações sobre a formação universitaria". (Artículo referente a una conferencia en la Universidade de Goiás), citado por Simoes, Roberto Porto, en Relaçoes públicas: funçao política, Sumus Editorial, Sao Paulo, 1995, p. 170.

17 Lolas Stepke, Fernando. "Siquiatría y noticia", Revista El Sábado El Mercurio, 19/02/ 2000, p. 19.

18 Morin, Edgard: "L'événement-sphinx", Communication № 18, p. 177.

19 Ibid., Rodrigo, p. 93.

20 Martínez Albertos, José Luis, "El mensaje informativo", A.T.E., Barcelona, 1977, p. 35.

21 Ibid., Rodrigo, p. 185.

22 Ver Gandy, Oscar, Beyond agenda-setting: information subsidies and public policy, Alex Publishing Corporation, Norwood, NJ, 1982.

23 Tagle, Matías y Ramírez, Paulo, "Problemas éticos en el periodismo actual: una mirada desde la acción profesional", Informe Final Dipuc 95/32 PM, Santiago de Chile, 1996, p. 9 (no publicado).

24 Ibid. , Tagle et al., pp. 9-12.

25 Ibid. , Tagle et al., p. 6.

26 Ibid., De Fontcuberta, p. 65.
27 Ver McCombs, M. y Shaw, D., "The agenda-setting functions of the mass media", Public Opinion Quarterly, 36, 1972.

28 Tuchman, G., La producción de la noticia. Estudio sobre la construcción de la realidad, Gustavo Gili, Barcelona, 1983, citado por Rodrigo, p. 51.

29 Tuchman, G., Making News, Free Press, New York, 1978, citado por van Dijk, en "La noticia como discurso", Paidós Comunicación, Barcelona, 1980, pp. 22-23.

30 Van Dijk, Teun A., La noticia como discurso, Paidós Comunicación, Barcelona, 1980, p. 23.

31 www.journalism.org/Report1.htm, citado por Gronemeyer, M. Elena, "¿Quién le cree a los periodistas?", Cuadernos de Información N¹3, Escuela de Periodismo, Pontificia Universidad Católica de Chile, Santiago, 1999, pp. 44-48.

32 Jack Fuller es presidente de la Tribune Publishing Company y autor del libro "News Values".

33 Semetko, Holli A. y Mandelli, Andreina, "Setting the agenda for cross-national research: bringing values into the concept", en McCombs, M., Shaw D., Weaver, D. (ed.), Communication and democracy: exploring the intelectual frontiers in agenda-setting theory, Lawrence Erlbaum, New Jersey, 1997, p. 200.

34 Blood, Deborah J. y Phillips, Peter C.B., "Economic headline news on the agenda: new approaches to understanding causes and effects", en op. cit. McCombs et al., p. 97.

35 Evans, Fred J., Managing the media, Quorum Books, Connecticut, 1987, p. 37

36 Schmertz, Herb y Novack, William, El silencio no es rentable. El empresario frente a los medios de comunicación, Planeta, Barcelona, 1987.

37 Ibid. , Alessandri et al., pp. 11-36.

38 Colombo, Furio, Ultimas noticias sobre el periodismo, Anagrama, 1997, p. 93.

39 Ibid., Tagle et al., p. 20 (las italicas han sido incorporadas por las autoras). 
40 Mamou, Yves, C'est la faute aux médias!, Payot, Paris, 1991, p. 86.

41 Ibid., Evans, p. 3.

42 D'Humières, Patrick, Management de la communication d'entreprise, Eyrolles, Paris, 1993, cap. 2.

43 Gómez, Paulina, La legitimación social de la empresa en Chile, proyecto de investigación, 09/1999, p. 5.

44 Kotler, Philip, "Megamarketing", Harvard Business Review, marzo-abril 1986. Para Kotler el megamarketing consiste en la aplicación estratégica y coordinada de habilidades económicas, sicológicas, políticas y de relaciones públicas para obtener la cooperación de una serie de intereses que permitan ingresar u operar en un o mercado dado. El megamarketing comprende las herramientas normales del marketing (las 4 Ps.) más poder y relaciones públicas.

45 Un buen acercamiento al pensamiento de Lucien Matrat, considerado el 'padre' de las relaciones públicas europeas, puede encontrarse en op. cit. Boiry, Philippe.

46 Simões, Roberto Porto: Relaçoes Públicas: Funçao Política. Sumus Editorial, Sao Paulo, 1995, p. 83.

47 Prudencio, Ramiro, ponencia presentada en mesa redonda "Comunicación corporativa: ¿facilitación o manipulación", Seminario Prensa y transparencia, Centro de Estudios de la Prensa, Pontificia Universidad Católica de Chile, octubre 1998. (Texto no publicado). Al momento de esta ponencia, Prudencio se desempeñaba como director regional de Burson-Marsteller.

48 Pérez Walker, Felipe, "Las comunicaciones externas y su valor en la creación de valor", ponencia presentada en II Congreso de Comunicación Corporativa, Pontificia Universidad Católica de Chile, octubre de 1995, pp. 6-7. (Texto no publicado). Al momento de esta ponencia, Pérez Walker se desempeñaba como gerente de comunicaciones de Coca-Cola de Chile.

49 D'Almeida, Nicole, L'entreprise à responsabilité illimitée, Liaisons, Paris, 1996, p. 36-38.

50 lbid., Colombo, p. 92.

51 Ramírez, Txema, Gabinetes de comunicación, Bosch,

\section{Comu-nicación, Barcelona, 1995, p. 20.}

52 Boyd, Robert A; presidente de l'Hydro-Québec y de la Societé de la Baie James. Declaración sostenida en 1978 en la Asociación de Relaciones Públicas de Québec, reproducida por Boiry, Philippe. Ver op. cit., p. 7.

53 Matrat, Lucien, citado por Boiry, op. cit. pp. 33-34.

54 Simões, op. cit., p. 213.

55 Luhmann, Niklas, "Legitimação pelo procedimento", Brasilia, Universidade de Brasilia, 1980, p.25, citado por Simões en Relaciones públicas: función política, El Ateneo, Barcelona, 1993, p. 129.

56 Serrano G., Enrique, Legitimación y racionalización, Antrophos, Filosofía Política, Barcelona, 1994, p. 7.

57 Txema Ramírez, en op.cit., p. 27, designa como gabinetes de comunicación a "las fuentes activas, organizadas y habitualmente estables que cubren las necesidades informativas tanto internas como externas de aquellas organizaciones y/o personas de relieve que desean transmitir de sí mismas una imagen positiva a la sociedad influyendo de esta forma en la opinión pública".

58 Drucker, Peter, La administración en una época de grandes cambios, Sudamericana, $3^{\mathrm{a}}$. edición, Buenos Aires, 1999, p. 68.

59 Ver Gronemeyer, M. Elena, "Periodismo ¿creible?", en Cuadernos de Información №10, Escuela de Periodismo, Pontificia Universidad Católica de Chile, Santiago, 1995.

60 lbid., Simões, "Relações ..." p. 221.

61 Foucault, Michel: Microfísica del poder, La Piqueta, Madrid, 1992, p. 140.

62 Ibid., Foucault, pp. 144 -145.

63 Ibid., Foucault, p. 149.

64 Gómez L., Paulina, ponencia "Medios de Comunicación y Gabinetes de Comunicación: ¿una relación legítima?", seminario Prensa y transparencia, Centro de Estudios de la Prensa, Pontificia Universidad Católica de Chile. 10/1998, p. 1. 
65 Ibid, Gómez, p. 2.

66 Drucker, Peter F., Las nuevas realidades en el estado y la política...en la economía y los negocios...en la sociedad y en la imagen del mundo, Sudamericana, Buenos Aires, 1990, p. 132.

67 Drucker, Peter F., La sociedad poscapitalista, Sudamericana , 4ª . Edición, Buenos Aires, 1994, p. 88.

$68 \mathrm{Cf}$. Brummer, James J., Corporate responsability and legitimacy: and interdisciplinary analysis, Greenwood Press, New York, 1991.

69 Fukuyama, Francis, Confianza, Atlántida, Buenos Aires, 1996, p. 388.

70 Ibid., pp.22-24.

71 Ibid. , p. 47.

72 Arrow, Kenneth J., economista y premio Nobel, The limits of organization, Norton, New York, 1974, p. 23, citado por Fukuyama, op. cit. p. 175.

73 Ibid., Drucker, "La sociedad...", p .86.

74 Cf. Drucker, "La sociedad...", p. 95.

75 Diccionario de la Lengua Española, Real Academia Española, 21 edición, Madrid, 1992, significado atribuido al término legitimidad.

\section{Referencias}

ABT, Clark C. (1981). Auditoría social para la gerencia, Diana, México.

ALESSANDRI, Francisca, EDWARDS, Cristóbal y PORATH, William (1999). Estudio de calidad informativa, Centro de Estudios de la Prensa, Facultad de Comunicaciones, Pontificia Universidad Católica de Chile, Santiago.

BERNAYS, Edward L. (1923). Crystallizing public opinion, versión española, Gestión 2000, Barcelona, 1998.

BOIRY, Philippe A. (1989). Les relations publiques ou la stratégie de la confiance, Eyrolles, Paris.
(1998). Las relaciones públicas o la estrategia de la confianza, Gestión 2000, Barcelona.

BRUMMER, James J. (1991). Corporate responsability and legitimacy: and interdisciplinary analysis, Greenwood Press, New York.

COLOMBO, Furio. (1997). Ultimas noticias sobre el periodismo, Anagrama, Barcelona.

D'ALMEIDA, Nicole (1996). L'entreprise à responsabilité illimitée, Liaisons, Paris.

DE CARLOS S., Carlos. (1988). Estrategia integral: responsabilidades sociales de las empresas e instituciones, Ediciones Universitarias de Valparaíso, Chile.

DE FONTCUBERTA, Mar. (1999). "Pauta y calidad informativa", Cuadernos de Información Nº13, Escuela de Periodismo, Pontificia Universidad Católica de Chile, Santiago.

D'HUMIÈRES, Patrick. (1993 ). Management de la communication d'entreprise, Eyrolles, Paris.

DRUCKER, Peter F. (1991). Las nuevas realidades en el estado y la política...en la economía y los negocios...en la sociedad y en la imagen del mundo, Sudamericana, $3^{\mathrm{a}}$. edición, Buenos Aires.

(1994). La sociedad poscapitalista, Sudamericana, $4^{\text {a }}$. edición, Buenos Aires.

(1999). La administración en una época de grandes cambios, Sudamericana, $3^{\text {a }}$. edición, Buenos Aires.

DURANDIN, Guy. (1995). La información, la desinformación y la realidad, Paidós, Comunicación/69, Barcelona.

ETKIN, Jorge R. (1993). La doble moral de las organizaciones. Los sistemas perversos y la corrupción institucionalizada, Mc Graw-Hill, España.

EVANS, Fred J. (1987). Managing the media, Quorum Books, Connecticut.

FOUCAULT, Michel. (1992). Microfísica del poder,La Piqueta, Madrid. 
FUKUYAMA, Francis. (1996). Confianza, Atlántida, Buenos Aires.

GALLO, Miguel Angel. (1980). Responsabilidades sociales de la empresa, Universidad de Navarra, Pamplona.

GANDY, Oscar. (1982). "Beyond agenda-setting: information subsidies and public policy", Alex Publishing Corporation, Norwood, New Jersey.

GRONEMEYER, M. Elena. (1995). "Periodismo ¿creíble?", Cuadernos de Información №10, Escuela de Periodismo, Pontificia Universidad Católica de Chile, Santiago

. (1999). "¿Quién le cree a los periodistas?", Cuadernos de Información №13, Escuela de Periodismo, Pontificia Universidad Católica de Chile, Santiago

KOTLER, Philip. (1986). "Megamarketing", Harvard Business Review, marzo-abril.

MAMOU, Yves. (1991). C'est la faute aux médias!, Payot, Paris.

MARTINEZ ALBERTOS, José Luis. (1977). El mensaje informativo, A.T.E., Barcelona.

McCOMBS, Maxwell y SHAW, Donald. (1972). "The agendasetting functions of the mass media", Public Opinion Quarterly, 36.

McCOMBS, Maxwell, SHAW, Donald y WEAVER, David (ed.). (1997). Communication and democracy: exploring the intelectual frontiers in agenda-setting theory, Lawrence Erlbaum, New Jersey.

MILON, Alain y JOUVE, Michel. (1996). Communication et organisations des entreprises. Approches critique et cases pratiques, Bréal, Paris.

MORIN, Edgard. "L'événement-sphinx", Communication, № 18, Paris.

PELLEGRINI, Silvia.(1999)."Medición de la calidad de la prensa en Chile", en Cuadernos de Información Nº13, Escuela de Periodismo, Pontificia Universidad Católica de Chile, Santiago.

PERALTA, Javier. (1995).“'Diarios de información económica: la diferencia existe", Cuadernos de Información №10, Escuela de Periodismo, Pontificia Universidad Católica de Chile, Santiago.

RAMÍREZ, Txema. (1995). Gabinetes de comunicación, Bosch Comunicación, Barcelona.

RODRIGO ALSINA, Miquel. (1996). La construcción de la noticia, Paidós Comunicación, Barcelona.

ROZAS, Eliana. (1996). "La selección noticiosa, entre la importancia y el interés", Cuadernos de Información N¹2, Escuela de Periodismo, Pontificia Universidad Católica de Chile, Santiago.

SCHMERTZ, Herb, NOVACK, William. (1987). El silencio no es rentable. El empresario frente a los medios de comunicación, Planeta, Barcelona.

SERRANO G., Enrique. (1994 ). Legitimación y racionalización, An-trophos, Filosofía Política, Barcelona.

SIMÕES, Roberto Porto. (1993). Relaciones Públicas, función política, El Ateneo, Barcelona.

(1995). Relaçoes Públicas: Funçao Política, Sumus Editorial, $3^{\mathrm{a}}$ edição revisada, São Paulo.

TAGLE, Matías y RAMIREZ, Paulo. (1996). Problemas éticos en el periodismo actual: una mirada desde la acción profesional, Informe final Dipuc 95/32 PM, Santiago de Chile.

VAN DIJK, Teun A.. (1990). La noticia como discurso. Comprensión, estructura y producción de la información, Paidós Comunicación, Barcelona.

VILLAFAÑE, Justo. (1993). Imagen positiva. Gestión estratégica de la imagen de las empresas, Pirámide, Madrid.

WEIL, Pascale. (1992). La comunicación global. Comunicación institucional y de gestión, Paidós, Barcelona.

XIFRA, Jordi. (1998). Lobbying. Cómo influir eficazmente en las decisiones de las instituciones públicas, Gestión 2000, Barcelona. 